\title{
Orexin-A and Orexin-B During the Postnatal Development of the Rat Brain
}

\author{
Irina I. Stoyanova - Wim L. C. Rutten • \\ Joost le Feber
}

Received: 5 June 2009/Accepted: 13 July 2009/Published online: 25 July 2009

(c) The Author(s) 2009. This article is published with open access at Springerlink.com

\begin{abstract}
Orexin-A and orexin-B are hypothalamic neuropeptides isolated from a small group of neurons in the hypothalamus, which project their axons to all major parts of the central nervous system. Despite the extensive information about orexin expression and function at different parts of the nervous system in adults, data about the development and maturation of the orexin system in the brain are a bit contradictory and insufficient. A previous study has found expression of orexins in the hypothalamus after postnatal day 15 only, while others report orexins detection at embryonic stages of brain formation. In the present study, we investigated the distribution of orexin-A and orexin-B neuronal cell bodies and fibers in the brain at three different postnatal stages: 1-week-, 2-week-old and adult rats. By means of immunohistochemical techniques, we demonstrated that a small subset of cells in the lateral hypothalamus, and the perifornical and periventricular areas were orexin-A and orexin-B positive not only in 2-week-old and adult rats but also in 1-week-old animals. In addition, orexin-A and orexin-B expressing neuronal varicosities were found in many other brain regions. These results suggest that orexin-A and orexin-B play an important role in the early postnatal brain development. The widespread distribution of orexinergic projections through all these stages may imply an involvement of the two neurotransmitters in a large variety of physiological and behavioral processes also including higher brain functions like learning and memory.
\end{abstract}

I. I. Stoyanova $(\varangle)$. W. L. C. Rutten · J. le Feber Institute for Biomedical Engineering and Technical Medicine MIRA, University of Twente, BSS, ZH 227, 7500 AE Enschede, The Netherlands

e-mail: stoyanovai@yahoo.co.uk
Keywords Orexin-A · Orexin-B · Postnatal brain development $\cdot$ Immunocytochemistry $\cdot$ Rat

\section{Introduction}

Orexin-A and orexin-B, also named by de Lecea et al. (1998) as hypocretin one and two (hypothalamic member of the incretin family of hormones), are neurotransmitters isolated from small subset of neurons specifically localized within and around the lateral hypothalamus ( $\mathrm{LH})$, posterior hypothalamus, dorsomedial hypothalamic nucleus (DMH), perifornical and subthalamic areas (Gautvik et al. 1996; Sakurai et al. 1998). The number of orexinergic neurons in the rat brain has been estimated to be only about 4,000 (Kilduff and Peyron 2000). These neurons express mRNA for a synthesis of the precursor prepro-orexin, giving rise to orexin-A and orexin-B, structurally related both to each other and to the intestinal hormone secretin. Orexin-A is a 33-amino acid peptide the sequence of which is found to be identical in human, rat, mouse and bovine, while orexin-B is a 28 -amino acid peptide that differs in two amino acids between the human, rat and mouse sequence (Sakurai et al. 1998).

The brain areas where orexinergic neurons are localized are known to be involved in the control of food intake (Anand and Brobeck 1951), but soon after their discovery, it was found that the orexins play a role also in the cardiovascular and neuroendocrine systems, energy homeostasis, thermogenesis, reproduction and locomotor activity (Lin et al. 1999; Sutcliffe and de Lecea 2000; Smart and Jerman 2002). Additionally, they were involved in nociception (Bingham et al. 2001), in the sleep regulation and the pathophysiology of narcolepsy (Chemelli et al. 1999; Lin et al. 1999), and higher brain functions as 
learning and memory as well (Fadel et al. 2002). Orexins might function as a global activator of brain systems, perhaps by orchestrating autonomic responses with selective attention (Hagan et al. 1999; Horvath et al. 1999). Besides the strong innervation of the hypothalamus, an extensive extrahypothalamic network of orexin-immunoreactive fibers suggests that the orexins may exert a strong modulatory action on many different brain functions and supports their description as "physiological integrators" (van den Pol et al. 1998; Mintz et al. 2001).

Despite the extensive information about orexin expression and function at different parts of the nervous system in adults, data about the development and maturation of the orexin system in the brain are a bit contradictory and insufficient. According to previous studies (de Lecea et al. 1998; van den Pol et al. 2001), orexins are expressed by embryonic days 18-20. Furthermore, mRNA coding for orexins is detectable at very low levels by the day of birth, followed by an increase to the maximum at postnatal day (PND) 20 (van den Pol et al. 2001). In contrast, as shown by Yamamoto et al. (2000), orexinergic neurons are not evident until PND 15 . This early postnatal period is critical for development of independent survival; therefore, a number of LH functions appear to become active early. Within PND 0-3, LH neurons develop glucosensitivity (Shibata et al. 1982) and respond to sensory stimulations (Fisher and Almi 1984). Orexin might provide part of the subcellular substrate for the complex and integrative role of the LH in development (van den Pol et al. 2001), and in this respect it is important whether these early responses coincide with the orexin system activation. For that reason, we undertook the present study with the aim of examining the expression of orexin-A and orexin-B in hypothalamic neurons and their projections in 1-week, 2-week-old and adult animals in order to clarify if there is any time-related difference in the orexin expression pattern. We also made an attempt to give an overview of the putative orexin functions during these early postnatal stages in the brain development.

\section{Methods}

Animals and Tissue Preparation

Adult Wistar rats (250-359 g b.w.), and rats at PND 7 and PND 14 (five animals for each age group) were used in this study. All housing facilities and procedures used were supervised and approved by the Animal Care and Use Committee of the University of Twente, The Netherlands and Trakia University, Stara Zagora, Bulgaria, and were consonant with the guidelines established by the NIH. The rats were deeply anesthetized with Ether and transcardially perfused, first with heparinized cold $0.9 \% \mathrm{NaCl}(1 \mathrm{U}$ heparin $/ \mathrm{ml}$ saline) followed by $4 \%$ paraformaldehyde in $0.1 \mathrm{M}$ phosphate saline (PBS; $\mathrm{pH}$ 7.4). After perfusion, the brains were removed, blocked and postfixed by immersion in the same fixative solution for $24 \mathrm{~h}$ at $4^{\circ} \mathrm{C}$, and then cryoprotected in $25 \%$ sucrose in PBS overnight at $4^{\circ} \mathrm{C}$ before cryosectioning. The brains were embedded in TissueTek OCT compound (Miles Inc., Elkhart, NI, USA), frozen, and $30 \mu \mathrm{m}$ thick sections were cut in a cryostat at $-20^{\circ} \mathrm{C}$. The sections were separated into five series, according to the method proposed by Guillery and Herrup (1997). After rinsing in 0.1 M PBS, each complete series of one-in-five frontal sections, stretching through the entire rostrocaudal dimension of the brain, were either processed for immunohistochemistry immediately or stored in cryoprotectant solution at $-20^{\circ} \mathrm{C}$.

\section{Immunocytochemistry}

The immunohistochemical staining procedure was performed on free-floating sections according to the $\mathrm{ABC}$ (avidin-biotin-horseradish peroxidase) method (Hsu et al. 1981). Briefly, specimens were pretreated with a solution of $1 \%$ sodium borohydrate in PBS. Appropriate washes in PBS followed this and subsequent incubations. A hydrogen peroxide $(0.3 \%$ in methanol/PBS for $30 \mathrm{~min})$ was used to inactivate endogenous peroxidase, and the background was blocked with $5 \%$ normal goat serum (NGS) and $1 \%$ bovine serum albumin (BSA) in $0.5 \%$ Triton X-100. Incubation in primary antibodies (Table 1) was for $20 \mathrm{~h}$ at room temperature (RT) and was followed by treatment for $2 \mathrm{~h}$ with biotinilated secondary antibody goat anti-rabbit IgG (1:500; Jackson ImmunoResearch, West Grove, PA, USA). The sections were then incubated for $1 \mathrm{~h}$ in $\mathrm{ABC}$ (1:500; Vector Labs, Burlingame, CA, USA), and after washing them ABC complex (Vector, $6.25 \mu \mathrm{l} / \mathrm{ml}$ of each compound in PBS) was applied. Following rinsing, peroxidase activity was visualized using 2.4\% SG substrate kit (Vector) in PBS for $5 \mathrm{~min}$ at room temperature. To reveal the precise location of labeled neurons and neuronal projections to the
Table 1 Source and dilution of the primary antibodies

\begin{tabular}{llll}
\hline Antibody & Source & Host & Dilution \\
\hline Orexin-A (PC362-100UL) & Calbiochem, Merck Chemicals, Nottingham & Rabbit & $1: 500$ \\
Orexin-B (GTX10982) & GeneTex Inc., San Antonio, TX, USA & Rabbit & $1: 1,000$ \\
\hline
\end{tabular}


cortex, we counterstained them with $0.5 \%$ Neutral red (Sigma, St. Louis, MO, USA). Finally, the sections were dehydrated in a graded series of alcohols, cleared in xylene and coverslipped with Entellan (Merck, Darmstadt, Germany).

Negative controls included sections that were incubated in the absence of primary antibody or in a presence of nonimmune normal serum in the same dilution as the primary antibody, as well as antigen-antibody preabsorption experiments with the native antigen at $4^{\circ} \mathrm{C}$ for $24 \mathrm{~h}$.

\section{Data Analysis and Photomicrograph Production}

For the assessment of orexin-A and orexin-B expression in the hypothalamus, sections from -0.92 to $-5.20 \mathrm{~mm}$ (from Bregma) were selected according to Coggeshall and Lekan (1996). After immunostaining, images were generated through $2.5 \times, 4 \times, 10 \times, 20 \times$ and $40 \times$ objectives, and the brain slices were photographed with an AxioCam MRC digital camera linked to a Zeiss Axioplan 2 research microscope. All digital images were matched for brightness in Adobe Photoshop 7.0 software.

\section{Results}

\section{Specificity}

No immunoreactivity for orexin-A or orexin-B was detected in the tissues when the primary or secondary antibody was replaced with normal serum (not shown). The immunoreactivity was readily discernible at the light microscopic level by the presence of a dark-gray immunoreactive product. Neuronal structures were considered to be immunopositive when their staining was clearly stronger than that in the background.

\section{Distribution of Orexin-A and Orexin-B Immunoreactivity}

In the brains from all three age groups, nearly all orexin-A and orexin-B positive cell bodies were found bilaterally, confined to the lateral hypothalamus at the level of the median eminence (Fig. 1a). A few labeled neurons were scattered in the dorsal and dorsomedial hypothalamic areas adjacent to the 3rd ventricle (Fig. 1b). The size of the neuronal cell bodies was smaller in 1-week-old animals (Fig. 2a, b) compared to that in 2-week-old (Fig. 3a, b) or mature brains (Fig. 4a, b), and their neurites were shorter and thinner. The orexin-A and orexin-B immunoreactivity often was asymmetrically expressed within the cell body, usually on one side of the nucleus (Fig. 2b). In 2-week-old brains, the immunoreactivity was more evenly distributed
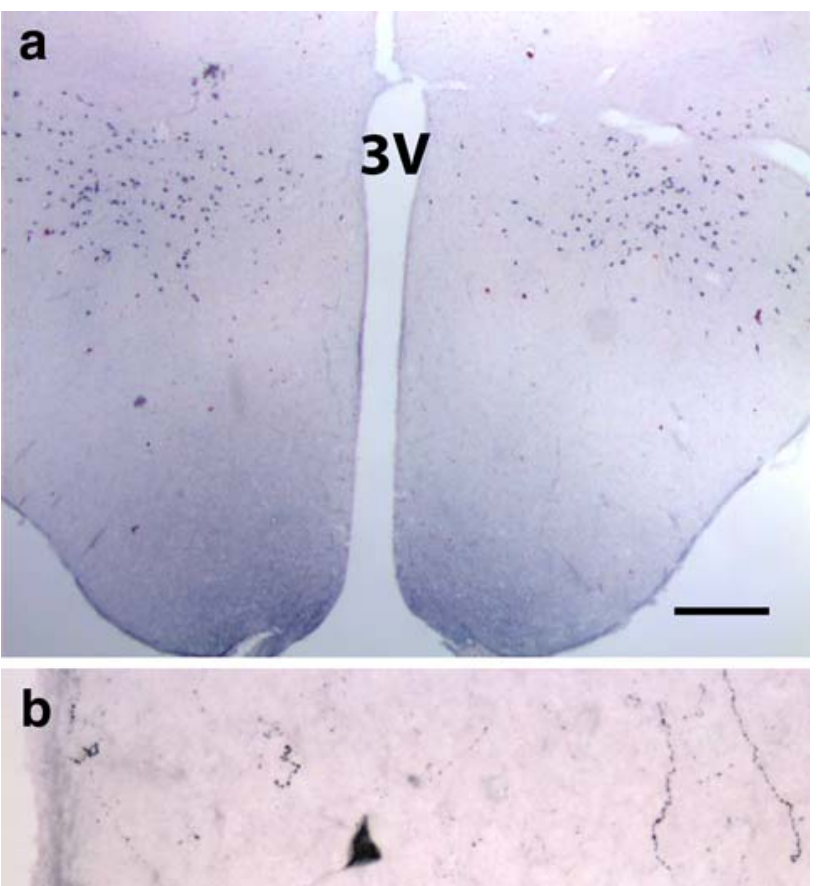

3V

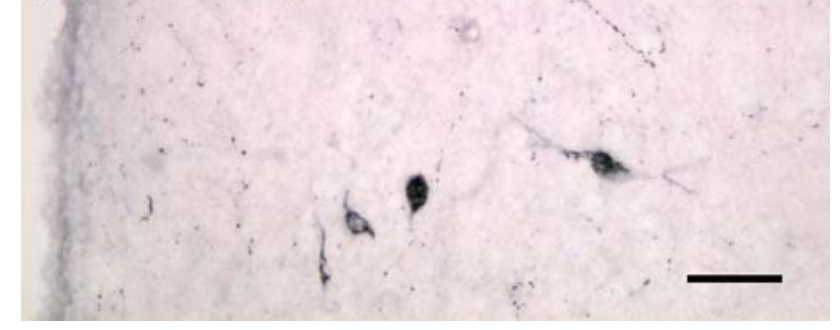

Fig. 1 Coronal section through the hypothalamus of adult rat labeled with orexin-B antiserum. a A low magnification showing orexinB-positive neurons distributed bilaterally in the lateral hypothalamic area. b Higher magnification of a section immunolabeled for Orexin-A. A few positive neurons are also seen in the dorsal and dorsomedial hypothalamic area, near the third ventricle (3 V). Scale bars: a $400 \mu \mathrm{m}$; b $50 \mu \mathrm{m}$

throughout the neuronal perikarya, and the neurites were better developed (Fig. 3a, b). In the adult brains, the neurons were similar in size and shape, fusiform to spherical, $20-30 \mu \mathrm{m}$ in diameter and had 2-5 primary dendrites with few secondary arborizations (Fig. 4a, b). Immunoreactivity was evenly distributed throughout the somata, excluding the nucleus.

A dense network of neuronal fibers expressing orexin-A and orexin-B-immunoreactivity was observed in the LH (Fig. 5a), paraventricular nucleus (PVN) (Fig. 5b) and strikingly, in the arcuate nucleus. It was also found in the adjacent median eminence (Fig. 5c). A fairly high density of orexin-positive fibers was seen close to the lateral and 3rd ventricles, several of which appeared to be in a close contact with the ependymal cells lining the ventricles 

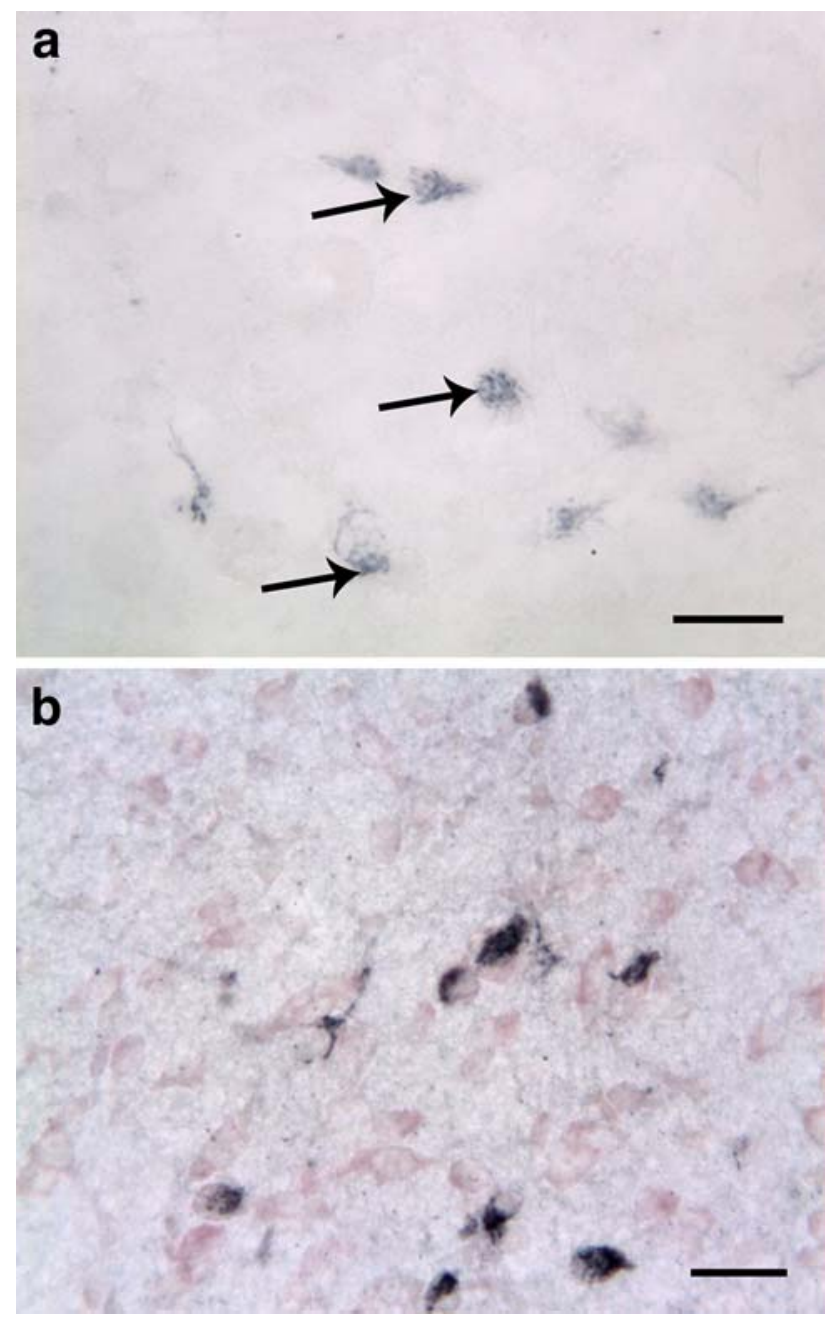

Fig. 2 Lateral hypothalamus of 1-week-old rat labeled with orexin-A (arrows) (a) and orexin-B (b) antisera. Sections were counterstained with neutral red in order to visualize nonimmunoreactive cells. The size of the neuronal perikarya is small, and the neurites are not well developed. The granular reaction product is expressed asymmetrically, usually on one side of the nucleus. Scale bars: a $30 \mu \mathrm{m}$; b $50 \mu \mathrm{m}$

(Fig. 5b). Some of the orexin-IR fibers protruded into the lumen of the ventricles or the cerebral aqueduct (Fig. 5d). Outside the hypothalamus, varicose immunoreactive fibers were found in brain regions of 1- and 2-week-old animals, where axons have been described in adult rats. Many of the fibers had large endings, suggestive of synaptic buttons (Fig. 6a). Orexin-A and Orexin -B immunoreactive fibers projected to different sites of the brain, including the cortex, the limbic system, particularly to the hippocampus, septal nuclei and the brain stem. In the brainstem, abundance of orexin-expressing projections was found in locus coeruleus, parabrachial (Fig. 7), dorsal raphe nuclei, central and lateral gray, while in the adjacent mesencephalic trigeminal nucleus (MTN) the density of orexin-immunoreactive fibers was moderate and varied along the
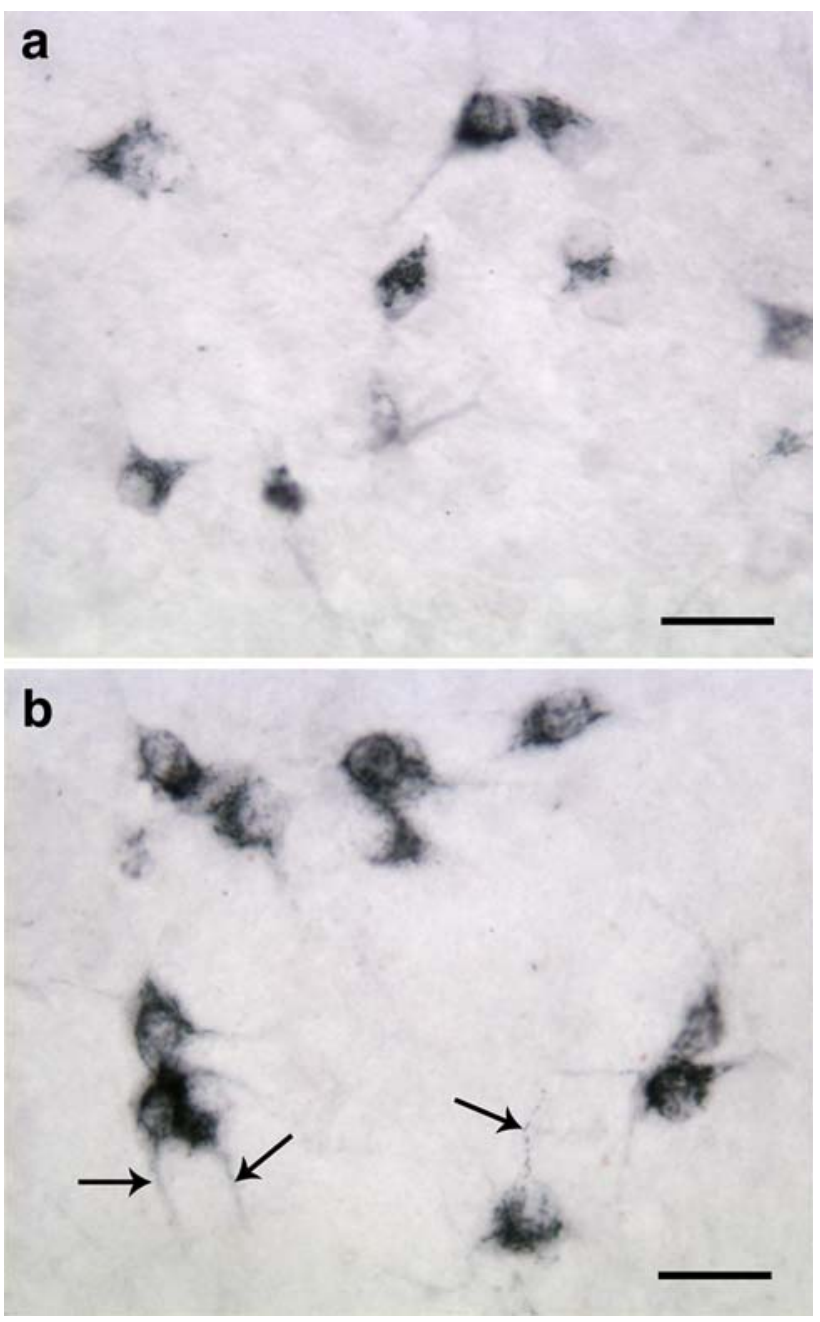

Fig. 3 Frontal sections of the hypothalamus of 2-week-old rat processed for immunohistochemical detection of orexin-A (a) and orexin-B (b). The size of the orexinergic neurons is bigger compared to those in 1-week-old animals (see Fig. 2), and the neurites are better developed (arrows). The granular immunoreaction product is more evenly distributed in the cytoplasm. Scale bars: $30 \mu \mathrm{m}$

rostrocaudal extension of the nucleus. It was more dense at the level of the inferior colliculus and sparse to very spars in the caudal part of MTN. Orexinergic fibers and terminal arborizations were found in direct apposition to, or coursing over the surface on MNT neurons of all sizes.

\section{Discussion}

In the present study, we demonstrate that a subset of cells in the $\mathrm{LH}$, the perifornical and paraventricular areas are orexin-A and orexin-B positive not only in adult rats but also in 1-week and 2-week-old animals. This finding is in consent with some previous observations of other groups (van den Pol et al. 2001), but it is in contrast with the 

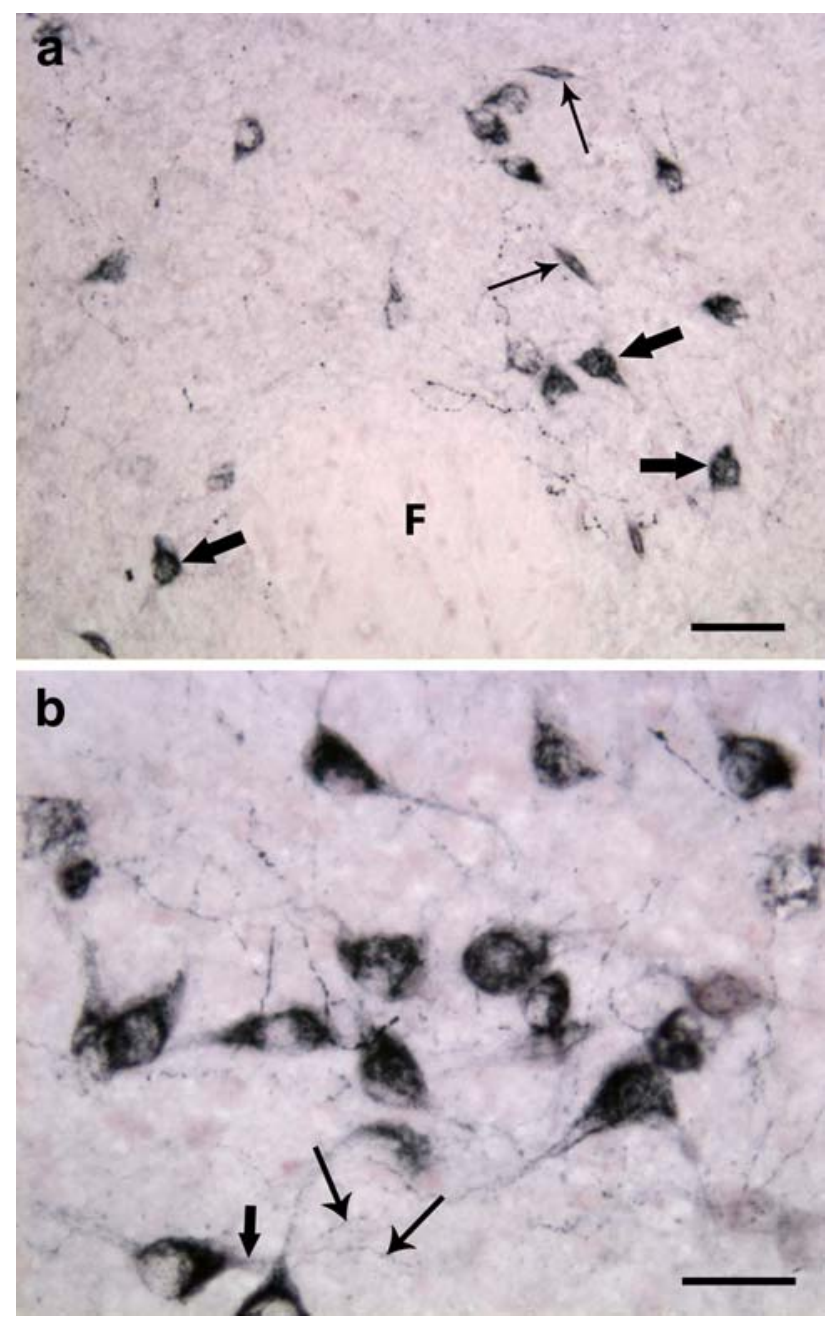

Fig. 4 Close-up of the lateral hypothalamus of adult rat. a Orexin-Aimmunoreactive neuronal pericarya and varicose neuronal fibers located in the perifornical area. The cell somata are well developed and two major types of neurons are well distinguishable: spindleshaped neurons (thin arrows) with two main neurites arising from the opposite poles of the cell body, and multipolar neurons (thick arrows) with several major neurites emerging from a stellate-shaped soma. F, fornix. (b) Higher magnification of orexin-B positive neurons. A primary dendrite is indicated with thick arrow, and thin arrows are pointing to two secondary arborizations. Scale bars: a $50 \mu \mathrm{m}$; b $30 \mu \mathrm{m}$

results of Yamamoto et al. (2000) who did not observe orexin-A and orexin-B immunoreactive cells and fibers before PND 15. The existence of the orexin system at early postnatal stages, which we demonstrate here, suggests that orexin-A and orexin-B might be important signaling molecules for brain development, as it has previously been shown for GABA and glutamate (Spoerri 1988; Ben-Ari et al. 1994; Constantine-Paton and Cline 1998; Hahm et al. 1999). GABA acts as a trophic substance promoting synaptogenesis or the synaptogenic capacity (Wolff et al. 1978), as also does glutamate, enhancing neuritic growth and stabilizing early synapses (Owens and Kriegstein 2002; Leinekugel 2003).

Orexin-A and orexin-B may take part in the two major events, which indeed play a significant role in neuronal development: formation of synaptically connected networks, regulated by neurotropic and neurotrophic factors and the emergence of bioelectrical network-wide activity patterns. In fact, although neurotransmitters are generally associated with neuronal communication in the mature brain, many of them have been shown to influence these two main aspects of brain development and maturation (Levitt et al. 1997; Meier et al. 1991; Owens and Kriegstein 2002). In vitro experiments indicated that a rapid synapse formation begins during the first week and reaches its maximum at day 21, as also does the activity of the network (Van Pelt et al. 2004). This qualitatively mimics the in vivo time course of development (Romijn et al. 1981; Van Huizen et al. 1985) and coincides with the appearance of the orexin-positive structures in the brain during the early postnatal stages, as we show here, which probably means that orexins take part in the synaptogenesis.

The neuronal activity is essential for the network formation and brain development in many aspects; especially, for modulation of the adhesion molecules (Itoh et al. 1995) and establishment of axonal connections (Penn et al. 1998). The consolidation of intrinsic connections during early brain development is possible only if there is synchronous network activity, which develops in immature neocortical networks shortly after neurogenesis and disappears before the onset of experience-dependent plasticity (Malenka and Nicoll 1997). The synchronous network activity triggers collective activation of silent synapses, a process that starts at day 6 and reaches its maximum at day 12 in vivo in rats (Voigt et al. 2005). As we demonstrate, in the hypothalamus of 1-week and 2-week-old rats there are orexinergic neurons, and despite the fact that they are smaller in size and their arborizations are not well developed, the electrophysiological studies of other research groups indicate that orexin-A and orexin-B already have a very strong excitatory effect (for a review see Cutler et al. 1999; van den Pol et al. 2001). In young hypothalamic neurons in vitro (cultured for 2 days), orexin-A and orexin-B increase postsynaptic activity directly (van den Pol 2001), while in older neurons (cultured for $>14$ days) orexins stimulate synaptic activity indirectly via enhancement of GABA and glutamate secretion (Gao and van den Pol 2000).

In the mature brain, GABA is the primary inhibitory transmitter; however, during the early postnatal stages of development, at the time when orexins begin to enhance activity, GABA is generally excitatory (Obrietan and van den Pol 1995; Chen et al. 1996). Thus, an orexin-mediated increase in the release of GABA and glutamate during early development might enhance excitatory postsynaptic 

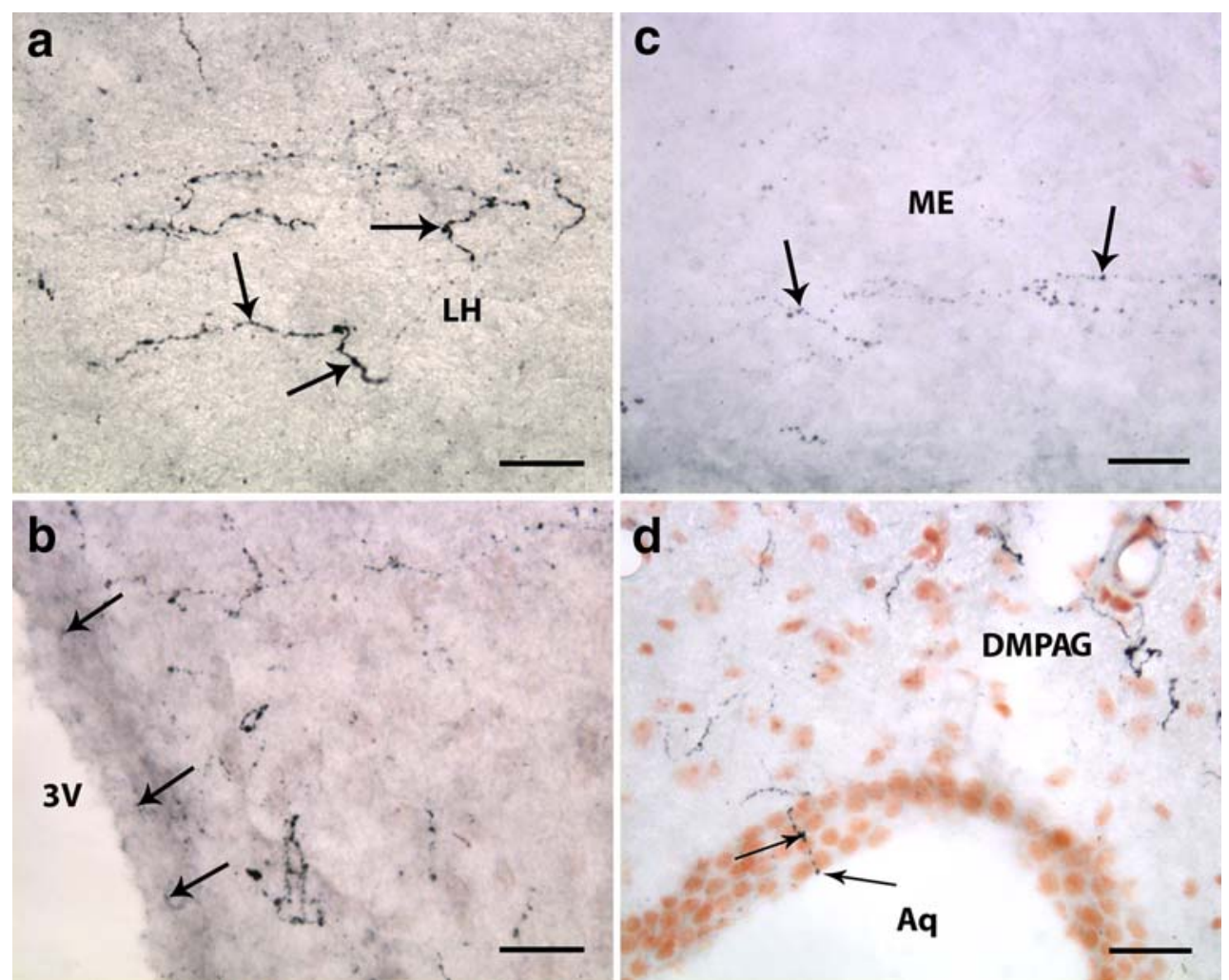

Fig. 5 Orexin-A and -B expressing neuronal fibers projecting to different parts of the brain of adult rat. a A dense network of orexin-A containing axonal varicosities (arrows) in the LH. b Micrograph illustrating the proximity of orexin-A positive fibers to the ventricular system. Some of the neuronal processes (arrows) protrude between the ependymal cells lining the third ventricle $(3 \mathrm{~V})$. c Moderate

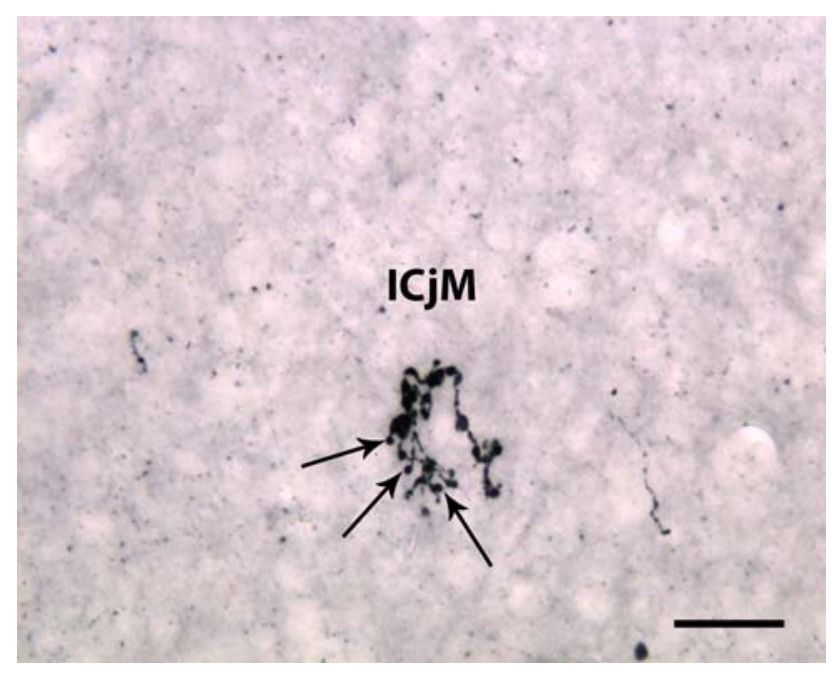

Fig. 6 Terminal arborizations of orexin-A-reactive projections to the cortex, the major island of Calleja (ICjM). Many of them have large endings suggestive of synaptic buttons (arrows). Scale bar: $30 \mu \mathrm{m}$

activity indirectly through these two classical neurotransmitters (van den Pol et al. 2001) and thereby orexin-A and orexin-B may stimulate the network formation and cell-to- density of orexin-B immunolabeled projections (arrows) to the external part of the median eminence $(M E)$. d Orexin-A reactive fibers at the level of the mesencephalon. Moderate density of the labeled varicosities, some of which protrude into the lumen of the cerebral aqueduct $(A q)$ (arrows). DMPAG, dorsomedial periaqueductal gray. Scale bars: $30 \mu \mathrm{m}$

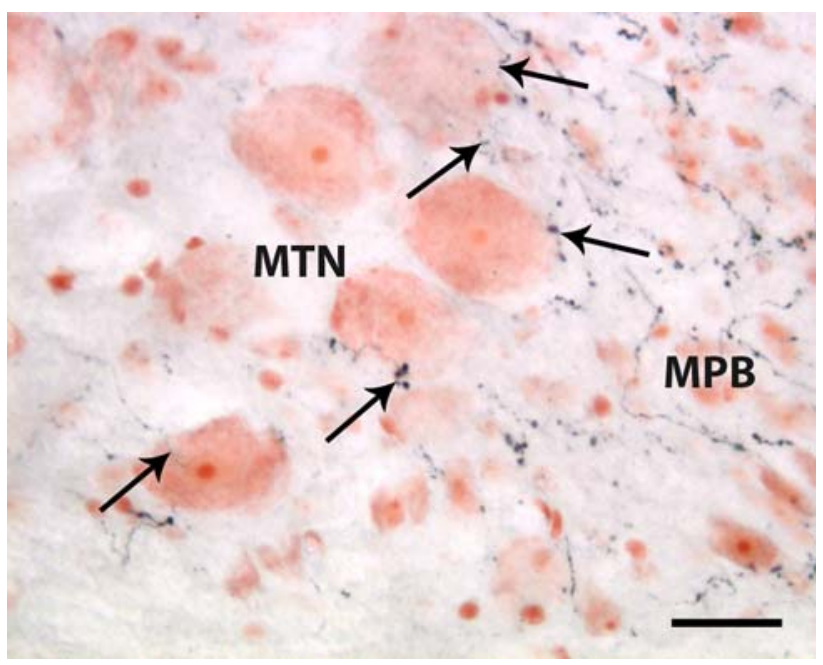

Fig. 7 Section from the pontine part of the brain stem labeled for orexin-A. In contrast to the very dense immunoreactive varicose fibers in the medial parabrachial nucleus $(M P B)$, the adjacent caudal part of the mesencephalic trigeminal nucleus $(M T N)$ expresses sparse density. Note that axonal varicosities and terminal button-like dots (arrows) are in close apposition to the MTN neuronal perikarya. Scale bar: $30 \mu \mathrm{m}$ 
cell interactions. Orexins may influence the early postnatal development and activity also via stimulation of neuronal plasticity, which depends on different neurotrophic factors (Lewin and Barde 1996); especially, brain-derived neurotrophic factor (BDNF) and neurotrophin-3 (NT-3) (Thoenen 2000). In a recent study on cultured cortical neurons, Yamada et al. (2009) demonstrated that chronic application of orexins significantly up-regulates the expression of NT-3 mRNA.

We found early postnatal orexin-IR axons in all medial and lateral regions of the hypothalamus, which suggests that orexin may exert not only a local feedback upon the neurons in the region where these neurotransmitters are synthesized, but also may play a role in the general modulation of a number of hypothalamic functions, which is in consent with the results of van den Pol et al. (1998).

We detected the densest arborization of orexinergic axons in the brain stem in the locus coeruleus (LC). The LC noradrenergic system gives rise to most of norepinephrine projections to all brain regions (Astor-Jones et al. 1995) and has directly been tied to a variety of brain functions, including the sleep-wake cycle, attention, learning and memory (Jouvet 1969; Robbins 1984; Sara and Devauges 1988). The particularly strong orexinergic innervation of LC, which we reveal in our investigation, underscores the potentially strong role that orexins might play in enhancing the activity of the LC noradrenergic system and entails orexins in the control of arousal and attention. In this respect, our findings in rat correspond well to the conclusions of Peyron et al. (2000) and Thannickal et al. (2000) that orexins are involved in the pathogenesis of sleep disorders such as narcolepsy-cataplexy in humans.

Unlike the results of van den Pol et al. (1998), we observed a relatively well-expressed orexinergic projections to the median eminence, as also reported by Chen et al. (1999). The median eminence represents the anatomical interface between brain and the anterior pituitary. It is the final point of converge of pathways from the CNS on the peripheral endocrine system, and thus the orexins could impinge on this system and alter the release of hormones.

The presence of orexin-A and orexin-B IR fibers in the MTN, which we show, provides further evidence that the central orexigenic system of the rat may participate in the autonomic control of feeding behavior. MTN is a unique structure, which includes primary sensory neurons innervating the masticatory muscle spindles and mechanoreceptors associated with the teeth (for details see Jerge 1963). However, little is known as to whether orexin-A and orexin-B projections innervate the nucleus (Zhang and Luo 2002; Stoyanova and Lazarov 2005). Our results clearly demonstrate that MTN receives a direct innervation by both orexins with somatotopic arrangement. While orexin-B fibers are more equally distributed, orexin-A-IR projections are predominantly found in the rostral part of the nucleus where the perikarya of the muscle spindle afferents are located. This leads to the conclusion that the hypothalamic orexin system may influence both the masticatory and proprioceptive processes at the level of the MTN.

In summary, the hypothalamic neurons of 1-week-old rats already express orexin-A and orexin-B IR, which may imply an involvement of these neurotransmitters in the brain development and maturation during the early postnatal stages. Orexins may play this role via different neurotrophic factors and direct or indirect activation of neuronal network activity. The distribution of orexin-A and orexin-B IR cell bodies and fibers at early postnatal stages is similar to that found in adult rat brain and is consistent with the potential roles for orexins in a wide variety of physiological and behavioral processes. In addition to the direct innervation of many targets in the CNS, neuronal activity of some parts of the brain could also be modulated by the orexin system indirectly, either via very dense orexinergic projections to nonspecific groups of neurons, or in paracrine manner via the orexins in the cerebro-spinal fluid, released by the protrusions of orexin-immunoreactive fibers into the ventricular system of the brain.

Acknowledgments This study is a part of the EU research project NEURoVERS-it. It was supported by grant MRTN-CT-2005-019247, the University of Twente, The Netherlands, and Trakia University, Stara Zagora, Bulgaria.

Open Access This article is distributed under the terms of the Creative Commons Attribution Noncommercial License which permits any noncommercial use, distribution, and reproduction in any medium, provided the original author(s) and source are credited.

\section{References}

Anand BK, Brobeck JR (1951) Localization of a "feeding center" in the hypothalamus of the rat. Proc Soc Exp Biol Med 77:323-324

Astor-Jones G, Shipley MT, Grzanna R (1995) The locus coeruleus, A5 and A7 noradrenergic cell groups. In: Paxinos G (ed) The rat nervous system. Sydney, Academic Press, pp 183-213

Ben-Ari Y, Tseeb V, Raggozzino D, Khazipov R, Gaiarsa JL (1994) Gamma-aminobutyric acid (GABA) a fast excitatory transmitter, which may regulate the development of hyppocampal neurons in early postnatal life. Prog Brain Res 102:261-273

Bingham S, Davey PT, Babbs AJ, Irving EA, Sammons MJ, Wyles M, Jeffrey P, Cutler L, Riba I, Johns A, Porter RA, Upton N, Hunter AJ, Parsons AA (2001) Orexin-A, an hypothalamic peptide with analgesic properties. Pain 92:81-90

Chemelli RM, Willie JT, Sintin CM, Elmquist JK, Scammell T, Lee C, Richardson JA, Williams SC, Xiong Y, Kisanuki Y, Fitch TE, Nakazato M, Hammer RE, Saper CB, Yanagisawa M (1999) Narcolepsy in orexin knockout mice: molecular genetics of sleep regulation. Cell 98:437-451

Chen G, Trombley P, van den Pol AN (1996) Excitatory actions of GABA in developing rat hypothalamic neurons. J Physiol (Lond) 494:451-464 
Chen TC, Dun SL, Kwok EH, Dun NJ, Chang JK (1999) Orexin Alike immunoreactivity in the rat brain. Neurosci Lett 260:161164

Coggeshall RE, Lekan HA (1996) Method for determining numbers of cells and synapses: a case for more uniform standards of review. J Comp Neurol 346:6-15

Constantine-Paton M, Cline HT (1998) LTP and activity-dependent synaptogenesis: the more alike they are, the more different they become. Curr Opin Neurobiol 8:139-148

Cutler DJ, Morris R, Sheridhar V, Wattam TAK, Holmes S, Petel S, Arch JRS, Wilson S, Buckingham RE, Evans ML, Leslie RA, Williams G (1999) Differential distribution of orexin-A and orexin-B immunoreactivity in the rat brain and spinal cord. Peptides 20:1455-1470

de Lecea L, Kilduff TS, Peyron C, Gao X-B, Foye PE, Danielson PE, Fukuhara C, Battenberg ELF, Gautvik VT, Bartkett FS, Frankel WN, van den Pol AN, Bloom FE, Gauthvik KM, Sutcliffe JG (1998) The hypocretins: hypothalamus-specific peptides with neuroexcitatory activity. Proc Natl Acad Sci USA 95:322-327

Fadel J, Bubser M, Deutch AY (2002) Differential activation of orexin neurons by antipsychotic drugs associated with weight gain. J Neurosci 22:6742-6746

Fisher RS, Almi CR (1984) Postnatal development of sensory influences on lateral hypothalamic neurons of the rat. Brain Res 314:55-75

Gao X-B, Van den Pol AN (2000) Melanin concentrating hormone: an inhibitory neuropeptide in the lateral hypothalamus. Soc Neurosci Abstr 26:1151

Gautvik KM, de Lecea L, Gautvik VT, Danielson PE, Tranque P, Dopazo A, Bloom FE, Sutcliffe JG (1996) Overview of the most prevalent hypothalamus-specific mRNAs, as identified by directional tag PCR substraction. Proc Natl Acad Sci USA 93:87338738

Guillery RW, Herrup K (1997) Quantification without pontification: choosing a method for counting objects in sectioned tissues. J Comp Neurol 386:2-7

Hagan JJ, Leslie RA, Patel S, Evans ML, Wattam TA, Holmes S, Benham CD, Taylor SG, Routledge C, Hemmati P, Munton RP, Ashmeade TE, Shah AS, Hatcher JP, Hatcher PD, Jones DN, Smith MI, Piper DC, Hunter AJ, Porter RA, Upton N (1999) Orexin A activates locus coeruleus cell firing and increases arousal in the rat. Proc Natl Acad Sci USA 96:10911-10916

Hahm JO, Cramer S, Sur M (1999) Pattern formation by retinal afferents in the ferret lateral geniculate nucleus: developmental segregation and the role of $N$-methyl-D-aspartate receptors. J Comp Neurol 411:327-345

Horvath TL, Peyron C, Diano S, Ivanov A, Aston-Jones G, Kilduff TS, van den Pol AN (1999) Hypocretin (orexin) activation and synaptic innervation of the locus coeruleus noradrenergic system. J Comp Neurol 415:145-159

Hsu SM, Raine L, Fanger H (1981) Use of avidin-biotin-peroxidase complex $(\mathrm{ABC})$ in immunoperoxidase techniques: a comparison between $\mathrm{ABC}$ and unlabeled antibody (PAP) procedures. J Histochem Cytochem 29:577-580

Itoh K, Stevens B, Schnachner M, Fields DR (1995) Regulated expression of the neural cell adhesion molecule L1 by specific patterns of neural impulses. Science 270:1369-1372

Jerge CR (1963) Organization and function of the trigeminal mesencephalic nucleus. J Neurophysiol 26:379-392

Jouvet M (1969) Biogenic amines and the states of sleep. Science 163:32-41

Kilduff TS, Peyron C (2000) The hypocretin/orexin ligand-receptor system: implication for sleep and sleep disorders. Trends Neurosci 23:359-365

Leinekugel X (2003) Developmental patterns and plasticities: the hippocampal model. J Physiol Paris 97:27-37
Levitt P, Harvey JA, Simansky K, Murphy EH (1997) New evidence for neurotransmitter influences on brain development. Trends Neurosci 20:269-274

Lewin GR, Barde YA (1996) Physiology of the neurotrophins. Annu Rev Neurosci 19:298-317

Lin L, Faraco J, Li R, Kadotani H, Rogers W, Lin X, Qiu X, de Jong PJ, Nishino S, Mignot E (1999) The sleep disorder canine narcolepsy is caused by mutation in the hypocretin (orexin) receptor 2 gene. Cell 98:365-376

Malenka RC, Nicoll RA (1997) Silent synapses speak up. Neuron 19:473-476

Meier E, Hertz L, Schousboe A (1991) Neurotransmitters as developmental signals. Neurochem Int 19:1-15

Mintz EM, van den Pol AN, Casano AA, Albers HE (2001) Distribution of hypocretin-(orexin) immunoreactivity in the central nervous system of Syrian hamsters (Mesocricetus auratus). J Chem Neuroanat 21:225-238

Obrietan K, van den Pol AN (1995) Developmental reversal of the role of GABA in elevating and depressing $\mathrm{Ca}^{2+}$. J Neurosci 15:5065-5078

Owens DF, Kriegstein AR (2002) Is there more to GABA than synaptic inhibition? Nature Rev 3:715-727

Penn AA, Riquelme PA, Feller MB, Shatz CJ (1998) Competition in retinogeniculate patterning by spontaneous activity. Science 279:2108-2112

Robbins TW (1984) Cortical noradrenalin, attention and arousal. Psychol Med 14:13-21

Romijn HJ, Habets MT, Mud MT, Wolters PS (1981) Nerve outgrowth, synaptogenesis and bioelectric activity in fetal rat cerebral cortex tissue cultured in serum-free, chemically defined medium. Develop Brain Res 2:583-589

Sakurai T, Ameliya A, Isgii M, Matsuzaki I, Chemelli RM, Tanaka H, Williams SC, Richardson JA, Kozlowski GP, Wilson S, Arch JRS, Buckingham RE, Haysen AC, Carr SA, Annan RS, McNulty DE, Liu W-S, Terrett JA, Elshourbagy NA, Bergsma DJ, Yanagisawa M (1998) Orexins and orexin receptors: a family of hypothalamic neuropeptides and $G$ protein-coupled receptors that regulate feeding behavior. Cell 92:573-585

Sara SJ, Devauges V (1988) Idazoxan, an alpha-2 antagonist, facilitates memory retrieval in the rat. Behav Neurol Biol $51: 401-411$

Shibata S, Oomura Y, Kita H (1982) Ontogenesis of glucose sensitivity in the rat lateral hypothalamus: a brain slice study. Brain Res 281:114-117

Smart D, Jerman JC (2002) Physiology and pharmacology of the orexins. Pharmacol Ther 94:51-61

Spoerri P (1988) Neurotrophic effect of GABA in cultures of embryonic chick brain and retina. Synapse 2:11-22

Stoyanova II, Lazarov NE (2005) Localization of orexin-A-immunoreactive fibers in the mesencephalic trigeminal nucleus of the rat. Brain Res 1054:82-87

Sutcliffe JG, de Lecea L (2000) The hypocretins: excitatory neuromodulatory peptides for multiple homeostatic systems, including sleep and feeding. J Neurosci Res 62:161-168

Thannickal TC, Moore RY, Nienhuis R, Ramanathan L, Guliani S, Aldrich M, Cornford M, Siegel JM (2000) Reduced number of hypocretin neurons in human narcolepsy. Neuron 27:469-474

Thoenen N (2000) Neurotrophins and activity-dependent plasticity. Prog Brain Res 128:183-191

van den Pol AN, Gao XB, Obrietan K, Kilduff T, Belousov A (1998) Pre- and postsynaptic actions and modulation of neuroendocrine neurons by a new hypothalamic peptide, hypocretin/orexin. J Neurosci 18:7962-7971

van den Pol AN, Patrylo PR, Ghosh PK, Gao XB (2001) Lateral hypothalamus: early developmental expression and response to hypocretin (orexin). J Comp Neurol 433:349-363 
Van Huizen F, Romijn HJ, Habets AMMC (1985) Synaptogenesis in rat cerebral cortex cultures is affected during chronic blockade of spontaneous bioelectrical activity by tetradotoxin. Develop Brain Res 19:67-80

Van Pelt J, Corner MA, Wolters PS, Rutten WLC, Ramakers GJA (2004) Longterm stability and developmental changes in spontaneous network burst firing patterns in dissociated rat cerebral cortex cell cultures on multielectrode arrays. Neurosci Lett 361:86-89

Voigt T, Opitz T, de Lima AD (2005) Activation of early silent synapses by spontaneous synchronous network activity limits the range of network connections. J Neurosci 25:4605-4615
Wolff JR, Joo F, Dames W (1978) Plasticity in dendrites shown by continuous GABA

Yamada N, Katsuura G, Tatsuno I, Kawahara S, Ebihara K, Saito Y, Nakao K (2009) Orexins increase mRNA expression of neurotrophin-3 in rat primary cortical neuron cultures. Neurosci Lett 450:132-135

Yamamoto Y, Ueta Y, Hara Y, Serino R, Nomura M, Shibuya I, Shirahata A, Yamashita H (2000) Postnatal development of orexin/hypocretin in rats. Mol Brain Res 78:108-119

Zhang J, Luo P (2002) Orexin B immunoreactive fibers and terminals innervate the sensory and motor nucleus of the jaw-elevator muscles in the rat. Synapse 44:106-110 